\title{
MIGRAÇÃO DE MINERAIS DE PANELAS BRASILEIRAS DE AÇO INOXIDÁVEL, FERRO FUNDIDO E PEDRA-SABÃo (ESTEATITO) PARA SIMULANTES DE ALIMENTOS ${ }^{1}$
}

\author{
Késia Diego QUINTAES ${ }^{2, *}$, Jaime AMAYA-FARFAN², Fernanda Mariana TOMAZINI², \\ Marcelo Antônio MORGANO ${ }^{3}$, Dilza M. B. MANTOVANI ${ }^{3}$
}

\section{RESUMO}

Os utensílios culinários podem liberar alguns componentes inorgânicos durante a cocção de alimentos. A migração destes pode ser interessante desde que ocorra em quantidades adequadas às necessidades nutricionais do usuário ou não existam implicações toxicológicas. Foi avaliada a migração de metais (Fe, Mg, Mn, Cr, $\mathrm{Ni}, \mathrm{Ca}, \mathrm{Zn}, \mathrm{Pb}, \mathrm{Cd}$ e $\mathrm{Hg}$ ) por espectrometria de emissão óptica, utilizando ácidos láctico e acético como simulantes do alimento em panelas de aço inoxidável (304), ferro fundido (GG-10) e pedra-sabão (esteatito), durante 15 cocções seqüenciais. O comportamento da migração durante cinco ciclos de estocagem a $22^{\circ} \mathrm{C}$ também foi estudado. Análise de regressão dos dados revelou que, em função do uso, as panelas de inox apresentam redução da migração de metais de forma rápida, enquanto as de pedra-sabão mostram um declínio suave na migração, contrastando com as de ferro, que apresentam aumento na migração de Fe e Mn com o uso contínuo. Em nenhum utensílio foi observada a liberação de metais pesados, como $\mathrm{Pb}, \mathrm{Cd}$ ou $\mathrm{Hg}$.

Palavras-chave: utensílios culinários; nutrição mineral; ácido láctico; ácido acético.

\section{SUMMARY}

MINERAL MIGRATION FROM STAINLESS STEEL, CAST IRON AND SOAPSTONE PANS (STEATITE) ONTO A FOOD SIMULANTS. Cookware may release some inorganic components into foods during cooking. Migration of ions could be of nutritional interest provided they do not pose a toxic hazard or are released in excess of the recommended amounts. In the present study the migration of $\mathrm{Fe}, \mathrm{Mg}, \mathrm{Mn}$, Cr, $\mathrm{Ni}, \mathrm{Ca}, \mathrm{Zn}, \mathrm{Pb}, \mathrm{Cd}$ and $\mathrm{Hg}$ from stainless steel (304), cast iron (GG-10) and soapstone (steatite) commercial cooking pans was evaluated in 15 sequential operations using lactic and acetic acids as food simulants. The migration patterns were also studied along five cycles of storage at $22^{\circ} \mathrm{C}$. Regression analysis of the data showed that while ions migrated out of the stainless steel pans in a rapidly decreasing fashion, the rate of migration from the stone utensils exhibited a slow and gradual decrease, in contrast with the increasing tendency observed for $\mathrm{Fe}$ and $\mathrm{Mn}$ in the cast iron pans. In no case was the release of heavy metals such as lead, cadmium or mercury observed. Keywords: Cooking utensils; mineral nutrition; lactic acid; acetic acid.

\section{1 - INTRODUÇÃO}

Durante o processamento e preparo, os alimentos permanecem por variados tempos de residência em recipientes industriais e utensílios domésticos onde pode haver alteração no conteúdo de nutrientes e até no sabor do alimento preparado. O impacto sensorial está parcialmente relacionado à migração de elementos presentes na composição do material do utensílio [12]. A migração de metais presentes nos utensílios culinários pode ser interessante quando há carência dos mesmos na alimentação do consumidor ou desinteressante quando há liberação de micronutrientes minerais ou metais pesados em quantidades que possam trazer efeitos adversos à saúde $[2,7,13]$.

Entre os primeiros materiais usados no Brasil na confecção de panelas está a pedra-sabão (esteatito), ainda usada em Minas Gerais. Esta rocha possui Mg, $\mathrm{Fe}, \mathrm{Ca}, \mathrm{Mn}, \mathrm{Ni}$, entre outros metais [13]. Entretanto, e apesar de que o conhecimento popular aponte um efeito positivo para o uso regular das panelas de pedra visando reduzir a incidência de anemia ferropriva, os trabalhos sobre migração com este material são escassos.

\footnotetext{
Recebido para publicação em 10/03/2003. Aceito para publicação em 13/05/2004 (001079).

2. Universidade Estadual de Campinas -DEPAN/FEA/UNICAMP. E-mail: kesia@unicamp.br

3. Instituto de Tecnologia de Alimentos (ITAL). E-mail: morgano@ital.org.br * A quem a correspondência deve ser enviada.
}

Em se tratando do ferro, o extenso uso deste metal perdeu espaço para o alumínio durante a segunda metade do século passado. Atualmente, estas panelas são fabricadas com liga de ferro fundido (GG-10), a qual contém além do ferro, certas quantidades de manganês e zinco. O uso das panelas de ferro está associado à prevenção de anemia ferropriva, devido à quantidade e biodisponibilidade do ferro liberado pelo material [1, 3].

Também contendo ferro encontramos o aço inoxidável 304 (inox 304) com 10\% de níquel, 18\% de cromo e aproximadamente $70 \%$ de ferro. Cabe lembrar que tanto o ferro como o cromo $\left(3^{+}\right)$são elementos dos quais a população mais pode sofrer de carência do que de excesso. Por sua vez, o níquel poderia ser tóxico, dependendo da quantidade ingerida $(\geq 250 \mathrm{mg} / \mathrm{kg}$ de dieta) [8, 14]. As panelas de inox 304 nacionais não foram ainda avaliadas tecnicamente quanto à dissolução metálica durante processo de cocção.

Os principais fatores que afetam a migração dos elementos componentes do material das panelas incluem o pH do alimento, o tempo que o alimento permanece em contato e o teor de água da preparação. A área de contato, temperatura de sistemas aquosos, agitação, presença de agentes quelantes no alimento e a própria qualidade da liga, são fatores que influenciam em menor grau a dissolução dos metais $[5,10,11]$.

Visando determinar o benefício nutricional e a inocuidade, o presente estudo objetivou avaliar a dissolução dos minerais: ferro (Fe), magnésio (Mg), manganês 
$(\mathrm{Mn})$, cromo $(\mathrm{Cr})$, níquel $(\mathrm{Ni})$, cálcio $(\mathrm{Ca})$, zinco $(\mathrm{Zn})$, chumbo $(\mathrm{Pb})$, cádmio $(\mathrm{Cd})$ e mercúrio $(\mathrm{Hg})$ de panelas brasileiras de inox 304, pedra-sabão (esteatito) e ferro fundido (GG-10), tanto durante 15 cocções seqüenciais quanto durante a estocagem de simulante de alimentos (ácidos láctico e acético). As panelas de aço inoxidável foram avaliadas quanto à dissolução de $\mathrm{Fe}, \mathrm{Cr}$, $\mathrm{Ni}, \mathrm{Mn}, \mathrm{Pb}, \mathrm{Cd}$ e $\mathrm{Hg}$, enquanto que as de ferro fundido para $\mathrm{Fe}, \mathrm{Mn}, \mathrm{Zn}, \mathrm{Pb}$, Cd e $\mathrm{Hg}$. As panelas de pedrasabão foram estudadas quanto à liberação de $\mathrm{Ca}, \mathrm{Mg}$, $\mathrm{Fe}, \mathrm{Mn}, \mathrm{Ni}, \mathrm{Pb}, \mathrm{Cd}$ e $\mathrm{Hg}$.

\section{2 - MATERIAL E MÉTODOS}

A fim de simular as condições de cocção, soluções de ácido acético a 0,88M (5\%) e ácido láctico a 0,1M foram preparadas no laboratório com água deionizada (18,2 M $\Omega$ ), ácido acético glacial (Merck, p.a.) e ácido láctico (Merck, p.a.). A vidraria empregada, como pipetas, béqueres e embalagens, foi material novo e previamente descontaminado com detergente (Extran, Merck) e ácido nítrico (Merck, p.a.) preparado a 20\% com água deionizada.

Os testes de cocção com cada simulante se realizaram em duplicata para as panelas novas de inox 304, do fabricante Tramontina ${ }^{\circledR}$, de ferro fundido (GG-10) e de vidro (Visions ${ }^{\circledR}$ ) e em triplicata para as panelas de pedra-sabão (esteatito). Antes do inicio das cocções, as panelas de pedra-sabão receberam tratamento (cura) com óleo vegetal refinado e calor [13] e as de ferro fundido foram curadas com óleo vegetal refinado, segundo recomendação do fabricante (Fundição Mineira Ltda).

Todas as panelas possuíam capacidade aproximada de 2 litros e foram codificadas pelo lado externo. Os valores de migração obtidos com as panelas de vidro serviram como branco para os demais. As panelas de pedra-sabão foram pesadas destampadas antes e no final do experimento, a fim de avaliar a erosão do esteatito, usando balança analítica eletrônica (Tecnal - AS 5500 ), com capacidade de $0,25 \mathrm{~g}$ até $5000 \mathrm{~g}$. A diferença de peso foi correlacionada com a migração dos metais analisados, aplicando o índice de correlação simples de Pearson. Na Tabela 1, podem ser observadas as condições experimentais das cocções com os simulantes.

TABELA 1. Condições do teste de migração dos elementos durante as cocções com simulantes de alimentos

\begin{tabular}{lcccc}
\hline Utensílios (n) & Simulante & Volume & Repetições & $\begin{array}{c}\text { Tempo de } \\
\text { cocção * }\end{array}$ \\
\hline $\begin{array}{l}\text { Aço inoxidável (2) } \\
\text { Ferro (2) }\end{array}$ & $\begin{array}{c}\text { Ácido acético } \\
(0,88 \mathrm{M})\end{array}$ & $1 \mathrm{~L}$ & 15 & 20 \\
$\begin{array}{l}\text { Pedra-sabão (3) } \\
\text { Vidro (2) }\end{array}$ & & & \\
$\begin{array}{l}\text { Aço inoxidável (2) } \\
\text { Ferro (2) }\end{array}$ & $\begin{array}{c}\text { Ácido láctico } \\
(0,1 \mathrm{M})\end{array}$ & $1 \mathrm{~L}$ & 15 & 20 \\
$\begin{array}{l}\text { Pedra-sabão (3) } \\
\text { Vidro (2) }\end{array}$ & & & \\
$\begin{array}{l}(n) \text { Número de panelas } \\
\text { * em minutos, contados a partir do momento de ebulição }\end{array}$ &
\end{tabular}

Antes do início da primeira cocção e entre as cocções, as panelas foram lavadas com detergente biode- gradável e esponja polimérica macia. O enxágüe foi feito em água corrente, concluindo com água deionizada.

Cada simulante foi fervido por 20 minutos, contados a partir do momento de ebulição. As panelas permaneceram tampadas durante a cocção, exceto por um período de $3 \mathrm{~min}$, quando se simulou a mistura do conteúdo com uma espátula de polipropileno. Quinze cocções seqüenciais foram efetuadas em cada panela, a fim de avaliar a migração no decorrer do tempo de uso do utensílio.

Após resfriamento, o volume residual foi medido (proveta nova, vidro Pirex), homogeneizado e coletada amostra em duplicata $(25 \mathrm{~mL})$. As amostras foram codificadas e armazenadas sob refrigeração $\left(4 \pm 2^{\circ} \mathrm{C}\right)$ até a determinação dos minerais.

Para o ensaio de migração durante a estocagem foram utilizadas duplicatas de panelas novas de inox, ferro fundido e vidro (branco) e, de triplicata de panelas de pedra-sabão, sendo que as de ferro e as de pedra foram curadas antes do início do experimento, segundo sua respectiva recomendação. Antes do início do teste e entre os ciclos, as panelas foram lavadas da forma descrita anteriormente. Um litro de solução de ácido acético $0,88 \mathrm{M}$ foi mantido por 24 horas dentro de cada uma das panelas tampadas, em superfície plana na temperatura de $22 \pm 2^{\circ} \mathrm{C}$.

O mesmo procedimento foi adotado para as panelas de vidro que serviram como branco para os resultados, uma vez que esse material não libera quantidades significativas dos metais estudados [12, 13]. Após o tempo de estocagem, a solução foi homogeneizada dentro da própria peça, sem ocasionar qualquer perda ou abrasão da superfície de ensaio. Para tanto foi empregada uma pipeta nova a qual era enchida e esvaziada diversas vezes dentro da própria peça. Amostras em duplicada $(\sim 25 \mathrm{~mL})$ foram coletadas, codificadas e estocadas sob refrigeração $\left(2 \pm 2^{\circ} \mathrm{C}\right)$ até a análise química.

A determinação e quantificação dos elementos presentes nas amostras foram efetuadas pela técnica de espectrometria de emissão óptica em plasma indutivamente acoplado, através do espectrômetro simultâneo BAIRD, modelo ICP 2000 (Massachusetts, USA). As médias das duplicatas foram usadas para os cálculos estatísticos, sendo deduzido destas o valor do branco de cada elemento. Análise de regressão linear foi aplicada a fim de verificar o comportamento da migração em função do uso ou estocagem.

Nas Tabelas 2 e 3 podem ser observadas as condições de operação do equipamento para determinação multielementar, estabelecidas utilizando-se o manganês para o canal de alinhamento do espectrômetro de emissão, conforme recomendação do fabricante. Foi efetuada a correção de radiação de fundo para todos os elementos determinados. As curvas analíticas definidas para cada elemento foram preparadas a partir de soluções-padrão dos metais (Titrisol, Merck) em concentração de $1000 \mathrm{mg} \mathrm{L}^{-1}$ e mostraram-se lineares em toda a faixa de trabalho, cobrindo todas as concentrações das amostras. As curvas analíticas foram prepa- 
radas em soluções de ácido lático $0,1 \mathrm{M}$ e em ácido acético $5 \%(\mathrm{v} / \mathrm{v})$, conforme o simulante usado. As faixas de concentração usadas na construção das curvas analíticas para cada elemento foram: $\mathrm{Ca}$ e $\mathrm{Mg}\left(0,25\right.$ a $\left.200 \mathrm{mg} \mathrm{L}^{-1}\right)$; Fe $\left(0,005\right.$ a $\left.20 \mathrm{mg} \mathrm{L}^{-1}\right)$; Mn e Ni $\left(0,005\right.$ a $\left.5 \mathrm{mg} \mathrm{L}^{-1}\right)$; Cr e $\mathrm{Zn}$ Cd $\left(0,0025\right.$ a 2,5mg L $\left.{ }^{-1}\right) ; \mathrm{Pb}\left(0,02\right.$ a 0,25mg L $\left.{ }^{-1}\right) ; \mathrm{Hg}(0,2$ a $\left.0,8 \mathrm{mg} \mathrm{L}^{-1}\right)$.

TABELA 2. Condições de operação do espectrômetro de emissão

\begin{tabular}{ll}
\hline Potência do plasma & $1,1 \mathrm{~kW}$ \\
Gás refrigerante $(\mathrm{Ar})$ & $6,5 \mathrm{~L} \mathrm{~min}^{-1}$ \\
Gás auxiliar (Ar) & $6,5 \mathrm{~L} \mathrm{~min}^{-1}$ \\
Vazão da amostra & $2,1 \mathrm{~mL} \mathrm{~min}^{-1}$ \\
Altura e observação vertical & $19 \mathrm{~mm}^{\mathrm{a}}$ \\
Pressão do nebulizador ${ }^{\mathrm{b}}$ & $3 \mathrm{bar}$
\end{tabular}

${ }^{\mathrm{a}}$ acima da bobina de indução; ${ }^{\mathrm{b}}$ nebulizador pneumático concêntrico

TABELA 3. Comprimento de onda para os elementos estudados, limite de detecção e de quantificação

\begin{tabular}{lccc}
\hline Elementos & $\lambda(\mathrm{nm})$ & Limite de detecção $\left(\mu \mathrm{g} \mathrm{L}^{-1}\right)$ & Limite de Quantificação $\left(\mu \mathrm{g} \mathrm{L}^{-1}\right)$ \\
\hline Cálcio & 317,93 & 6,0 & 20,0 \\
Ferro & 259,94 & 1,2 & 4,0 \\
Níquel & 231,60 & 0,4 & 1,3 \\
Magnésio & 279,08 & 41,0 & 140,0 \\
Manganês & 257,67 & 0,5 & 1,7 \\
Zinco & 213,86 & 0,9 & 3,0 \\
Cromo & 267,71 & 0,8 & 2,7 \\
Chumbo & 220,35 & 4,0 & 13,3 \\
Mercúrio & 253,65 & 50,0 & 170,0 \\
Cádmio & 226,50 & 0,9 & 3,0 \\
\hline
\end{tabular}

Limite de Detecção: determinado como 3 vezes o desvio padrão de 10 brancos; Limite de Quantificação: determinado como 10 vezes o desvio padrão de 10 brancos

\section{3 - RESULTADOS E DISCUSSÃO}

\section{1 - Cocção de ácido acético e ácido láctico}

Nos extratos obtidos com as panelas de inox foram determinados os seguintes elementos: Fe, Cr, Ni e Mn. Nos produtos da cocção em panelas de ferro fundido, determinou-se: Fe, $\mathrm{Zn}$ e $\mathrm{Mn}$ e, das panelas de pedrasabão, Ca, Mg, Fe, Mn e Ni. Além destes, foi investigada a presença dos metais pesados $\mathrm{Cd}, \mathrm{Pb}$ e $\mathrm{Hg}$ em amostras aleatórias dos extratos dos simulantes usados nos três tipos de panelas. As amostras retiradas das panelas de vidro foram analisadas com respeito aos metais pesados, além de $\mathrm{Fe}, \mathrm{Mn}, \mathrm{Ni}, \mathrm{Ca}, \mathrm{Mg}, \mathrm{Zn}$ e $\mathrm{Cr}$. Os valores encontrados neste caso foram mínimos e/ou nulos (Tabela 4), sendo sistematicamente utilizados como 'brancos' para as demais panelas.

- Aço inoxidável 304. A migração dos elementos Fe, $\mathrm{Cr}$, Ni e Mn da panela de inox, foi iniciada de forma relativamente elevada, mas tendo logo na segunda cocção alcançado níveis reduzidos. Os resultados estão apresentados nas Figuras 1 e 2 .
TABELA 4. Valores de migração dos metais $\mathrm{Fe}, \mathrm{Mn}, \mathrm{Ni}, \mathrm{Ca}$, $\mathrm{Mg}, \mathrm{Zn}$ e $\mathrm{Cr}$ extraídos com ácido acético a $0,88 \mathrm{M}$ em panelas de vidro "Visions"

\begin{tabular}{lcc}
\hline Elementos & $\begin{array}{c}\text { Quantidade }\left(\mathrm{mg} \mathrm{L}^{-1}\right) \text { em ácido acético } \\
\text { 0,88M após 20 minutos em ebulição }\end{array}$ & $\begin{array}{c}\text { Quantidade }\left(\mathrm{mg} \mathrm{L}^{-1}\right) \text { em ácido acético } \\
0,88 \mathrm{M} \text { após } 24 \mathrm{~h} \text { em contato }\left(\mathrm{T}=22 \pm 2^{\circ} \mathrm{C}\right)\end{array}$ \\
\hline $\mathrm{Fe}$ & 0,0270 & 0,0600 \\
$\mathrm{Mn}$ & 0,0000 & 0,0000 \\
$\mathrm{Ni}$ & 0,0030 & 0,0010 \\
$\mathrm{Ca}$ & 0,0900 & 0,0170 \\
$\mathrm{Mg}$ & 0,0120 & 0,0160 \\
$\mathrm{Zn}$ & 0,0000 & 0,0000 \\
$\mathrm{Cr}$ & 0,0005 & 0,0030 \\
\hline
\end{tabular}

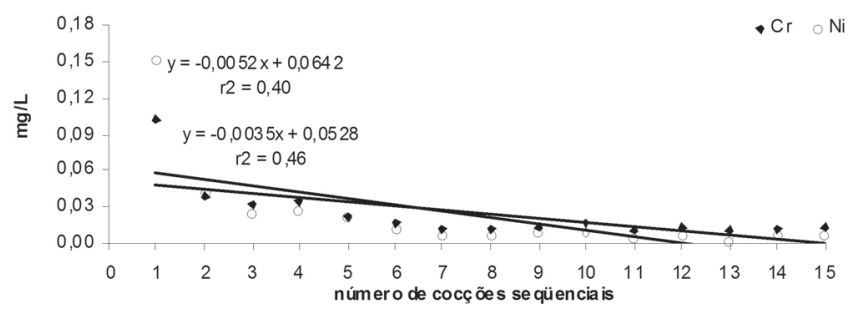

FIGURA 1. Migração de $\mathrm{Cr}$ e Ni em panelas $(\mathrm{n}=2)$ de aço inoxidável 304 após 20 minutos com ácido láctico $(0,1 \mathrm{M})$ em ebulição.

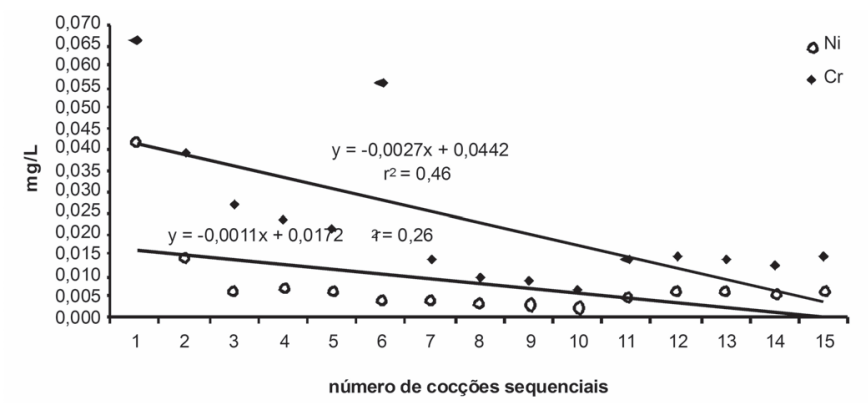

FIGURA 2. Migração de $\mathrm{Cr}$ e $\mathrm{Ni}$ em panelas $(\mathrm{n}=2)$ de aço inoxidável 304 após 20 minutos com ácido acético $(0,88 \mathrm{M})$ em ebulição.

Tanto o Fe como o Mn, derivados das panelas de inox, tiveram comportamento migratório similar ao exibido pelos elementos $\mathrm{Cr}$ e Ni nas Figuras 1 e 2. Outros trabalhos já evidenciaram que há maior migração metálica na primeira cocção com utensílios de aço inoxidável [6, 9]. KULIGOVSKI \& HALPERIN [8] utilizando ácido acético 0,88M mantido em ebulição por cinco minutos em panelas de inox, observaram migração de 0,01 a $0,31 \mathrm{mg} / \mathrm{L}$ de $\mathrm{Cr}$ e 0,01 a 0,2 $1 \mathrm{mg} / \mathrm{L}$ de Ni. Outros autores, utilizando ácido láctico $0,1 \mathrm{M}$ em contato por uma hora com panelas de inox, verificaram que concentrações de 0,06 a 0,09mg/L de $\mathrm{Cr}$ e de $0,02 \mathrm{mg} / \mathrm{L}$ de $\mathrm{Ni}$ eram extraídas [2]. No presente experimento com panelas de aço inoxidável, o ácido láctico extraiu maiores quantidades dos elementos estudados, em relação ao ácido acético. Em ambos os casos, todavia, as quantidades lixiviadas (Figuras 1 e 2) não parecem representar toxicidade à saúde humana [14]. 
- Ferro fundido GG 10. As panelas de ferro fundido liberaram quantidades expressivas de $\mathrm{Fe}$, sendo que o ácido acético se mostrou consideravelmente mais ativo na extração, do que o láctico. Enquanto a liberação de Fe variou entre 50 e 400mg/ L no ácido láctico, a extração foi cinco vezes superior na solução de ácido acético (Figura 3). É sabido que a acidez favorece a migração do Fe de panelas de ferro [3]. CHENG \& BRITTIN [4], em experimento envolvendo 50 cocções seqüenciais com molho de tomate e maçã, constataram que a migração de $\mathrm{Fe}$ em panelas novas de ferro é reduzida já nas duas primeiras vezes de uso. A seguir, as panelas de ferro continuam liberando quantidades constantes e expressivas de Fe para o meio.

A tendência de migração crescente do Fe era esperada ao se considerar que a área superficial do metal da panela sofre um aumento com o processo microscópico de erosão. Essa lógica, entretanto, não explicaria a lixiviação decrescente observada com o $\mathrm{Zn}$.

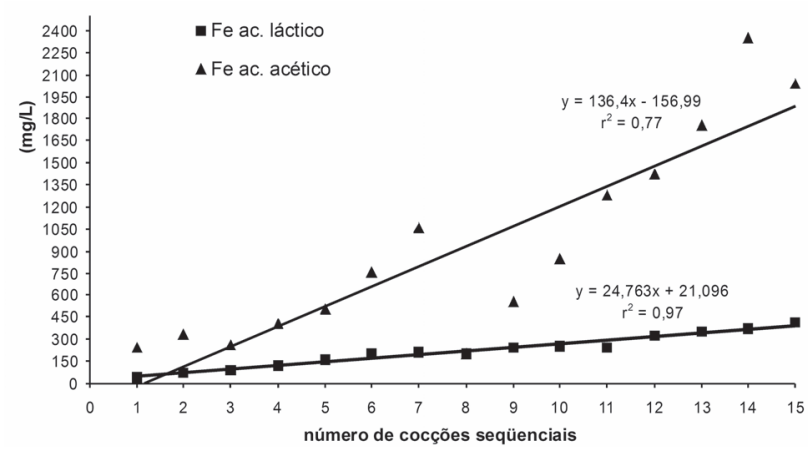

FIGURA 3. Migração de Fe em panelas de ferro fundido $(n=2)$ após 20 minutos com ácido láctico $(0,1 \mathrm{M})$ em ebulição e com ácido acético $(0,88 \mathrm{M})$ em ebulição

Cabe destacar que quando usado o ácido acético $(0,88 \mathrm{M})$ como meio extrator a ferrugem resultante da corrosão foi notável. Tal fato fez com que as duas panelas usadas no teste recebessem novamente o tratamento de cura recomendado pelo fabricante. O efeito desse procedimento pode ser observado na linha superior da Figura 3, onde se nota uma sensivel redução na migração de ferro entre a sétima e oitava cocção. O tratamento da cura neste caso reduziu significativamente a migração de $\mathrm{Fe}, \mathrm{Zn}$ e $\mathrm{Mn}$ para o meio extrator.

Para o elemento $\mathrm{Mn}$, foi verificado que sua migração reduziu com o aumento no número de vezes de uso da panela quando o simulante era o ácido acético, ficando nula a partir da décima-segunda cocção. Já quando usado o ácido lático como simulante, foi verificada forte tendência ao aumento na migração de $\mathrm{Mn}$ (Figura 4). A migração de $\mathrm{Zn}$, variou de forma decrescente entre 0,015 e 0,002mg/L em ácido láctico, contra 4,8 a 2,8mg/L, quando em ácido acético (dados não apresentados em separado).

Apesar do zinco e do manganês serem componentes da liga de ferro fundido comercial (GG-10), não encontramos trabalhos na literatura que quantifiquem esta migração e possibilitem a comparação dos resultados obtidos.

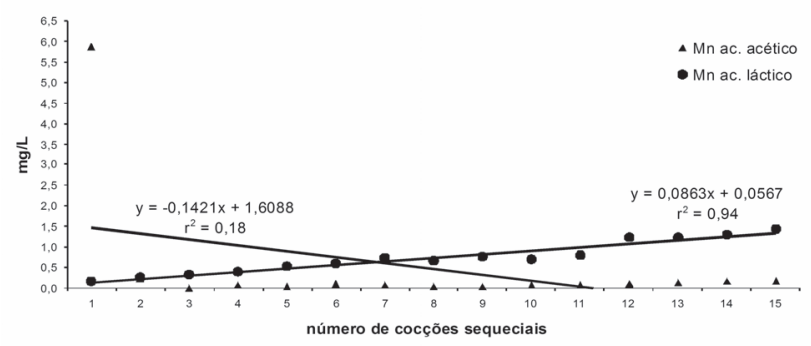

FIGURA 4. Migração de $\mathrm{Mn}$ em panelas de ferro fundido $(\mathrm{n}=2)$ após 20 minutos com ácido láctico $(0,1 \mathrm{M})$ em ebulição e com ácido acético $(0,88 \mathrm{M})$ em ebulição

- Pedra sabão. Os extratos obtidos das cocções em panelas de pedra-sabão curadas, mostraram liberação de $\mathrm{Ca}>\mathrm{Mg}>\mathrm{Fe}>\mathrm{Mn}>\mathrm{Ni}$, nesta ordem. Esta migração pode ser verificada a seguir nas $\mathrm{Fi}^{-}$ guras 5 a 8.

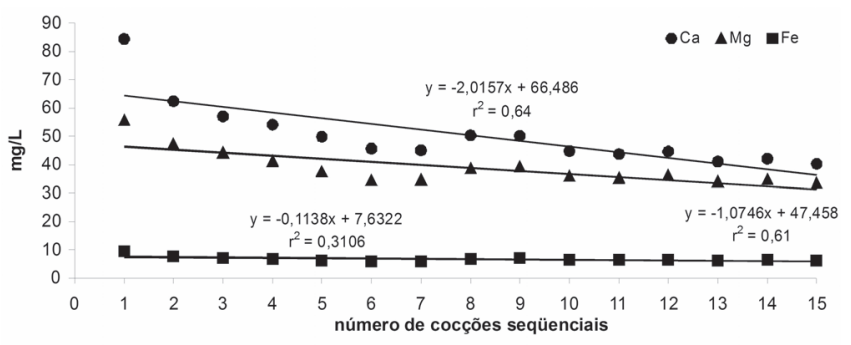

FIGURA 5. Migração de $\mathrm{Ca}, \mathrm{Mg}$ e $\mathrm{Fe}$ de panelas $(\mathrm{n}=3)$ de pedra-sabão (esteatito, curadas), após 20 minutos com ácido láctico $(0,1 \mathrm{M})$ em ebulição.

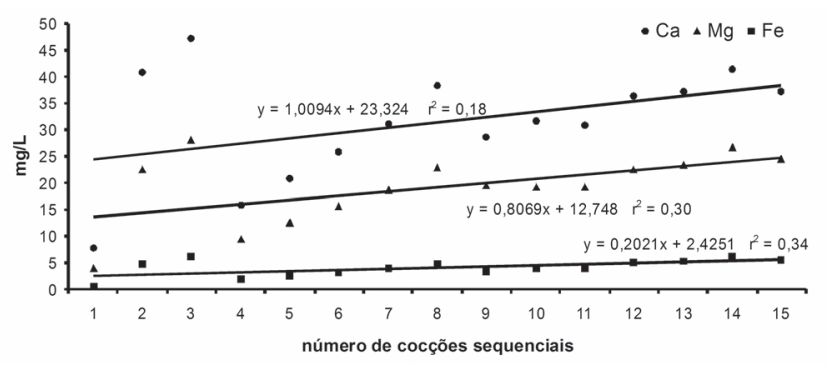

FIGURA 6. Migração de $\mathrm{Ca}, \mathrm{Mg}$ e $\mathrm{Fe}$ em panelas $(\mathrm{n}=3)$ de pedra-sabão (esteatito, curadas), após 20 minutos com ácido acético $(0,88 \mathrm{M})$ em ebulição.

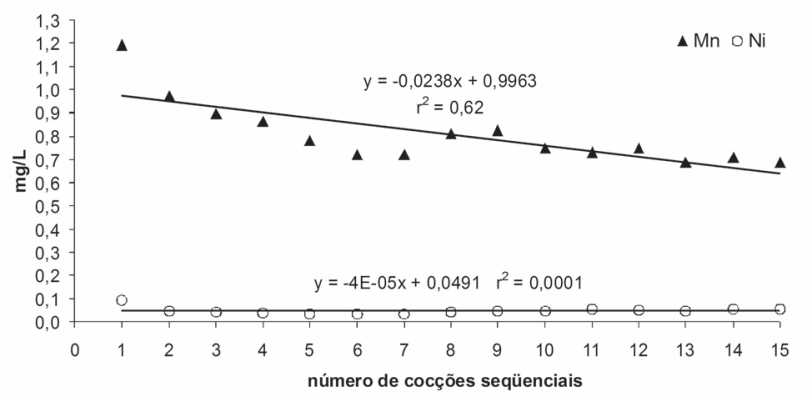

FIGURA 7. Migração de Mn e Ni em panelas (n=3) de pedrasabão (esteatito) curadas após 20 minutos com ácido láctico $(0,1 \mathrm{M})$ em ebulição. 


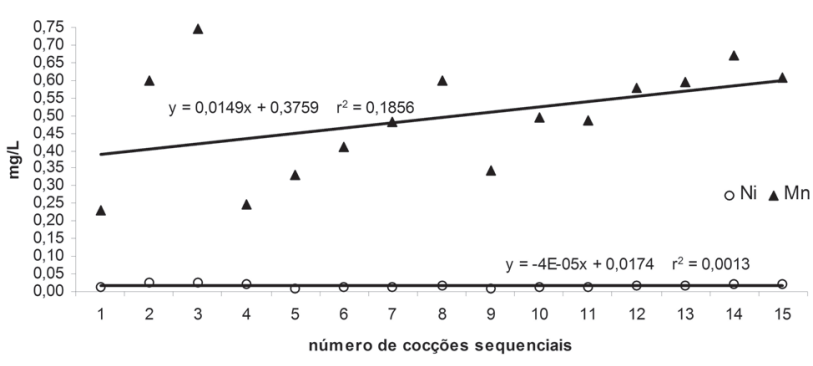

FIGURA 8. Migração de Mn e Ni em panelas $(n=3)$ de pedrasabão (esteatito) curadas após 20 minutos com ácido acético $(0,88 \mathrm{M})$ em ebulição.

As panelas de pedra-sabão liberaram quantidades significativas de $\mathrm{Ca}, \mathrm{Mg}$ e $\mathrm{Mn}$. Quando em uso com ácido láctico, foi notada leve redução na migração destes elementos conforme o acréscimo no número de vezes dos utensílios. Por outro lado, foi verificado ligeiro aumento quando em uso o ácido acético. Já a migração de Ni com ambos os simulantes não representa toxicidade, sendo insignificante $(<0,025 \mathrm{mg} / \mathrm{L})$ e constante em relação à freqüência de uso dos utensílios testados. Estes dados estão de acordo com o obtido anteriormente por QUINTAES et al. [13], que observaram migração expressiva de $\mathrm{Ca}, \mathrm{Mg}$, Fe e Mn usando como extrator um simulante de alimento mantido em ebulição por $45 \mathrm{mi}$ nutos em panelas de pedra-sabão curadas. Neste caso, os autores reportaram que a migração de Ni foi inferior a $0,025 \mathrm{mg} / \mathrm{L}$ e constante durante 20 cocções seqüenciais.

Ainda em relação às panelas de esteatito, foi verificada a perda de peso, média entre a primeira e a décima-quinta cocção, como sendo de $8,33 \pm 1,56 \mathrm{~g}$, ou seja, uma perda de 0,26 a $0,4 \%$ do peso inicial. Trabalho anterior envolvendo cocções seqüenciais com ácido acético 0,88M mostrou perdas de 10 até 30g [13].

Por intermédio da correlação de Pearson foi notado que a perda de peso apresentada individualmente por cada panela de pedra-sabão estava diretamente associada com a migração total de ferro e magnésio obtida após 15 cocções seqüenciais com ácido acético $(0,88 \mathrm{M})$. Quanto maior a perda de peso do utensílio, maior era a migração total de ferro e de magnésio. Tal evidência pode ser observada na Tabela 5.

TABELA 5. Correlação de Pearson aplicada entre a diferença de peso e o total de metais obtidos após 15 cocções seqüenciais com solução de ácido acético $(0,88 \mathrm{M})$ em três panelas de pedra-sabão

\begin{tabular}{ccccccc}
\hline Panela de pedra-sabão & $\begin{array}{c}\text { Fe total } \\
(\mathrm{mg})\end{array}$ & $\begin{array}{c}\text { Mn total } \\
(\mathrm{mg})\end{array}$ & $\begin{array}{c}\text { Ca total } \\
(\mathrm{mg})\end{array}$ & $\begin{array}{c}\text { Mg total } \\
(\mathrm{mg})\end{array}$ & $\begin{array}{c}\text { Ni total } \\
(\mathrm{mg})\end{array}$ & $\begin{array}{c}\text { Diferença de } \\
\text { peso* }(\mathrm{g})\end{array}$ \\
\hline $\mathrm{X}$ & 51,91 & 6,80 & 442,92 & 262,42 & 0,26 & 6,70 \\
$\mathrm{Y}$ & 63,09 & 8,47 & 506,71 & 298,18 & 0,23 & 8,50 \\
$\mathrm{Z}$ & 66,89 & 6,97 & 463,28 & 303,54 & 0,27 & 9,80 \\
\hline $\begin{array}{l}\text { Correlação de Pearson } \\
\text { (metal/diferença peso) }\end{array}$ & 0,98 & 0,19 & 0,40 & 0,95 & 0,20 & \\
\hline
\end{tabular}

* Peso inicial - Peso final (após 15 cocções)
Abaixo, na Figura 9 podem ser observados os teores de ferro liberados até a quinta cocção seqüencial de ácido acético $(0,88 \mathrm{M})$ nos três tipos de panelas avaliados pelo estudo. Fica evidente que o ferro fundido é o material mais susceptível a liberação de ferro para o meio extrator.

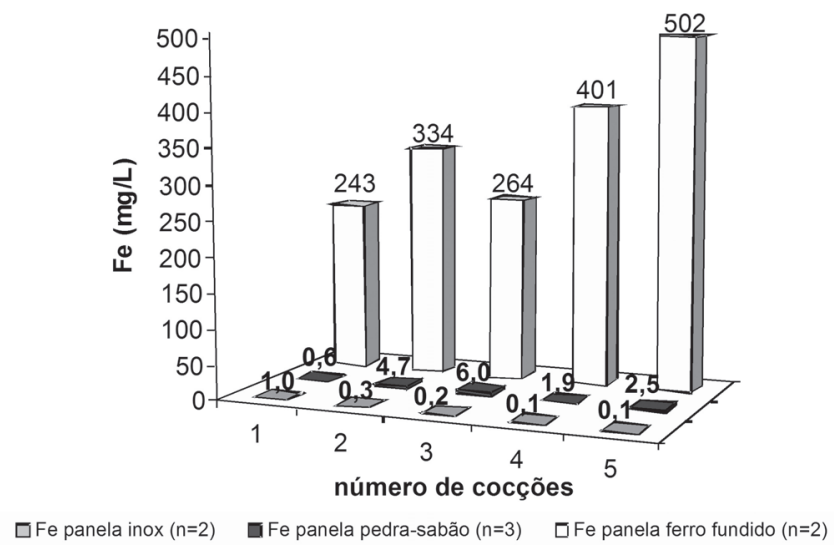

FIGURA 9. Comparação da migração de $\mathrm{Fe}$ em panelas de pedra-sabão (esteatito) curadas, inox e ferro fundido durante 5 cocções seqüenciais de ácido acético $(0,88 \mathrm{M})$ mantido em ebulição por 20 minutos.

\section{2 - Estocagem de ácido acético}

Em se tratando dos ciclos de estocagem com ácido acético $0,88 \mathrm{M}$, foi verificado que as panelas de inox liberaram quantidades inexpressivas de todos os elementos pesquisados ( $\mathrm{Fe}, \mathrm{Cr}, \mathrm{Mn}$ e $\mathrm{Ni}$ ), sendo mínima nas duas primeiras vezes de estocagem e nulas nas demais estocagens.

Na Tabela 6 são mostrados os valores da migração de $\mathrm{Ca}, \mathrm{Fe}, \mathrm{Mn}, \mathrm{Mg}$ e Ni das panelas de pedra-sabão e de $\mathrm{Zn}$, Mn e Fe das panelas de ferro fundido durante a estocagem. Essas últimas panelas apresentaram forte tendência ao aumento da migração de Fe e Mn com o incremento do número de exposições ao ácido acético 0,88M.

TABELA 6. Migração de elementos presentes nas panelas de pedra-sabão curadas e de ferro fundido durante

5 ciclos de estocagem de 24 horas com ácido acético a $22^{\circ} \mathrm{C}( \pm 2)^{*}$

\begin{tabular}{ccccccccc}
\hline \multirow{2}{*}{ Ciclos } & \multicolumn{4}{c}{ Pedra-sabão curada $(\mathrm{n}=3)$} & \multicolumn{4}{c}{ Ferro fundido curada $(\mathrm{n}=2)$} \\
\cline { 2 - 9 } & \multicolumn{1}{c}{$\mathrm{Ca}$} & $\mathrm{Fe}$ & \multicolumn{1}{c}{$\mathrm{Mn}$} & \multicolumn{1}{c}{$\mathrm{Mg}$} & \multicolumn{1}{c}{$\mathrm{Ni}$} & \multicolumn{1}{c}{$\mathrm{Zn}$} & \multicolumn{1}{c}{$\mathrm{Mn}$} & \multicolumn{1}{c}{$\mathrm{Fe}$} \\
\hline 1 & 40,49 & 0,77 & 0,11 & 3,03 & 0,030 & 0,15 & 1,19 & 304,2 \\
2 & 67,84 & 1,02 & 0,17 & 10,78 & 0,012 & 0,34 & 1,99 & 711,3 \\
3 & 40,64 & 4,91 & 0,59 & 19,96 & 0,038 & 0,17 & 3,54 & 2290,1 \\
4 & 67,08 & 7,89 & 0,97 & 32,71 & 0,059 & 0,37 & 6,20 & 3013,0 \\
5 & 38,58 & 3,39 & 0,49 & 16,03 & 0,020 & 0,37 & 15,41 & 3117,4 \\
\hline
\end{tabular}

*valores médios em mg/L

As panelas de pedra-sabão apresentaram acréscimo na migração de $\mathrm{Ca}, \mathrm{Fe}, \mathrm{Mn}, \mathrm{Mg}$ e $\mathrm{Ni}$ até o quarto ciclo, reduzindo a migração um pouco no último ciclo de exposição. Com relação ao $\mathrm{Ni}$, o lixiviado das panelas 
de pedra-sabão curadas continham maiores teores de $\mathrm{Ni}$ se comparados às cocções, iniciando no primeiro ciclo com 0,030mg/L, chegando ao nível máximo de $0,59 \mathrm{mg} / \mathrm{L}$ no quarto ciclo e reduzindo para $0,020 \mathrm{mg} / \mathrm{L}$ no quinto. Considerando que um adulto tem como limite de tolerância de ingestão máxima o valor de $1 \mathrm{mg} /$ dia [14], longos períodos de estocagem de alimentos ácidos prontos deveriam ser evitados nesse tipo de material.

\section{3 - Metais pesados}

Com relação aos metais pesados, foi verificado que nenhum dos utensílios testados liberou quantidades mesuráveis de $\mathrm{Pb}, \mathrm{Cd}$ ou $\mathrm{Hg}$, seja durante a cocção com os dois simulantes ou mesmo durante a estocagem por 24 horas com ácido acético $0,88 \mathrm{M}$. Tal dado confirma as informações anteriormente relatadas para o utensílio de pedra-sabão, onde a migração desses metais foi insignificante durante cocção com ácido acético a 3 e a 5\% [13]. Desta forma, os três tipos de utensílios testados foram considerados seguros, ou seja, que não oferecem risco à saúde humana com relação aos referidos minerais pesados, se utilizados nas condições do estudo.

\section{4 - CONCLUSÕES}

Os utensílios testados apresentaram perfis de migração distintos e susceptíveis à variação, conforme o tipo de simulante e a aplicação do utensílio (cocção ou estocagem). Tanto as panelas de aço inoxidável como as de ferro fundido não apresentaram implicações toxicológicas sob as condições de teste, sendo que as de ferro fundido poderiam contribuir significativamente na melhor adequação da alimentação de certos grupos populacionais em termos de ferro. Já as panelas de pedra-sabão liberaram quantidades consideráveis de Ca, $\mathrm{Mg}, \mathrm{Fe}$ e Mn durante a operação de cocção. Entretanto, a estocagem de alimentos nestas panelas, especialmente aqueles com alto teor de água e ácidos, deve ser executada com cautela, uma vez que o tempo de contato influi consideravelmente na liberação de níquel. Os resultados obtidos com os produtos de aço inox podem ser de utilidade na indústria de alimentos. Considerando ainda que o esteatito, o aço inox e o ferro fundido são materiais susceptiveis à abrasão, os dados aqui apresentados são válidos para superfícies não perturbadas por processos de polimento após cada ciclo de uso.

\section{5 - REFERÊNCIAS BIBLIOGRÁFICAS}

[1] ADISH, A.A.; ESREY, S.A.; GYORKOS, T.W.; JEANBAPTISTE, J.; ROJHANI, A. Effect of consumption of food cooked in iron pots on iron status and growth of young children: a randomised trial. Lancet, v. 353, n. 9154, p. 712-716, 1999.
[2] AGARWAL, P.; SRIVASTAVA, S.; SRIVASTAVA, M.; PRAKASH, S.; RAMANAMURTHY, M.; SHIRIVASTAV, R.; DASS, S. Studies on leaching of $\mathrm{Cr}$ and $\mathrm{Ni}$ from stainless steel utensils in certain acids and in some Indian drinks. Sci. Tot. Environ., v. 199, n. 3, p. 271-275, 1997.

[3] COUTSOUCOS, S.M.; COLLI, C. Iogurte preparado em panela de ferro: uma alternativa para fortificação de alimentos com ferro. Hig. Alim., v. 8, n. 29, p. 14-17, 1994.

[4] CHENG, Y.J.; BRITTIN, H.C. Iron in food: effect of continued use of iron cookware. J. Food Sci., v. 56, n. 2, p. 584-585, 1991.

[5] CHENG, X.L.; MA, H.Y.; CHEN, S.H.; YU, R.; CHEN, X.; YAO, Z.M. Corrosion of stainless steel in acid solutions with organic sulfur-contaning compounds. Corr. Sci., v. 41, n. 4, p. 321-333, 1999.

[6] FLINT, N.G.; PACKIRISAMY, S. Purity of food cooked in stainless steel utensils. Food Add. Contam., v. 14, n. 2, p. 115-126, 1997.

[7] KAKADE, V.; AGTE, V. Effect of using iron utensils visa-vis teflon-coated non stick wares on ionisable iron content of traditional vegetarian foods. J. Food Sci. Tech. (Mys), v. 34, n. 5, p. 427-430, 1997.

[8] KULIGOWSKI, J.; HALPERIN, K.M. Stainless steel cookware as a significant source of nickel, chromium, and iron. Arch. Environ. Contam. Toxic., n. 23, v. 2, p. 211-215, 1992.

[9] KUMAR, R.; SRIVASTAVA, P.K.; SRIVASTAVA, S.P. Leaching of heavy metals (Cr, Fe and $\mathrm{Ni}$ ) from stainless steel utensils in food simulants and food materials. Bull. Environ. Contam. Toxic., v. 53, n. 2, p. 259-266, 1994.

[10] LIUKKONEN-LILJA, H.; PIEPPONE, S. Leaching of aluminium from dishes and packages. Food Add. Contam., v. 9, n. 3, p. 213-223, 1992.

[11] PARK, J.; BRITTIN, H.C. Increase iron content of food due to stainless steel cookware. J. Americ. Diet. Ass., v. 97, n. 6, p. 659-661, 1997.

[12] PARK, J.; BRITTIN, H.C. Iron content, sensory evaluation, and consumer acceptance of food cooked in iron utensils. J. Food Qual., v. 23, n. 2, p. 205-215, 2000.

[13] GUINTAES, K.D.; AMAYA-FARFAN, J.; MORGANO, M.A.; MANTOVANI, D.M.B. Soapstone (steatite) cookware as a source of minerals. Food Add. Contam., v. 19, n. 2, p. 134-143, 2002.

[14] TRUMBO, P.; YATES, A.A.; SCHLICKER, S.; POSS, M. Dietary reference intakes: vitamina A, vitamina $\mathrm{K}$, arsenic, boron, chromium, copper, iodine, iron, manganese, molybdenum, nickel, silicon, vanadium, and zinc. J. Am. Diet. Ass., v. 101, n. 3, p. 294-301, 2001 .

\section{6 - AGRADECIMENTOS}

Os autores agradecem à Oro Preto Art's, Tramontina, SA, pela doação dos utensílios testados e à Fundição Mineira Ltda. (FUMIL) pelos utensílios cedidos e o apoio financeiro. 